\title{
Dynamics of collapsing fluidized beds and its application in the simulation of pulsed fluidized beds
}

\author{
Yongsheng Nie *, Dayou Liu \\ Instimute of Mechanics, Chinese Academy of Sciences, Beijing. China
}

Received 20 March 1998; received in revised form 4 June 1998

\begin{abstract}
A new method to study collapsing process of fluidized bed was proposed. The method is based on the analysis of the pressure variation during collapse. A model is proposed to describe the pressure variation on any location of the bed during collapse. Three kind of particles were fluidized by air and the pressure variation after shutting down the gas supply was measured by pressure transducers and simulated by the proposed model. The simulated results were in good agreement with the experimental data. The paraneters of the fluidized bed, such as bubble fraction $\alpha_{h}$, particle fraction in dense phase $\alpha_{p}$, bubble velocity $u_{h}$ and slip velocity of particle $u_{1}$, can be estimated from the measured pressure data by using the proposed model. The model was also used to calculate the pressure variation in pulsed fluidized beds with low frequency. (C) 1998 Elsevier Science S.A. All rights reserved.
\end{abstract}

Keywords: Bed collapse; Pressure; Model; Pulsed fluidized beds

\section{Introduction}

Bed collapsing technique has been widely used to study the behavior of a fluidized bed. It is attractive because of its simplicity and its potential for rapid determination. A number of workers have applied it for the measurement of the properties of dense phase and bubbles in bubbling fluidized beds. such as dense phase voidage $[1-3]$ : sedimentation velocity and expansion ratio of the dense phase [4]: and fraction and rising velocity of bubbles [5]. It has also been used in powder classification and evaluation of the quality of fluidization [6].

At present, the primary method to study collapsing process is by following the movement of the bed surface by photographic techniques after a sudden termination of the gas supply and the pictures need to be analyzed one by one, then the variation of the bed surface location can be plotted $[1-4]$. This is a time consuming procedure. An optical-fibre tracking set was developed by the Institute of Chemical Metallurgy, Academia Sinica which made the measurement more convenient and precise, but the device is complex and expensive [7].

In our work. pressure transducers were used to record the pressure variation during the collapsing process. Measuring the pressure variation is a better way to study collapse because it is simpler and faster than other methods. In this paper, we will analyze the collapsing process and propose a model to

\footnotetext{
* Corresponding author
}

describe the pressure variation during the collapsing process, then use the model to estimate the parameters of fluidized bed and simulate the collapsing process.

The gas-solid contact efficiency can be much improved in pulsed fluidized beds [8.9], however little work has been done on the dynamics of pulsed fluidized beds. We carried out a study of pulsed fluidized beds recently and will use the proposed model to simulate the pressure variation in pulsed fluidized beds with low frequency.

\section{Mathematical model}

When the gas supply of the fluidized bed is shut off abruptly at $t=0$, the bed height will vary with time as shown in Fig. 1. At first, bubbles ascend through the bed, leading to

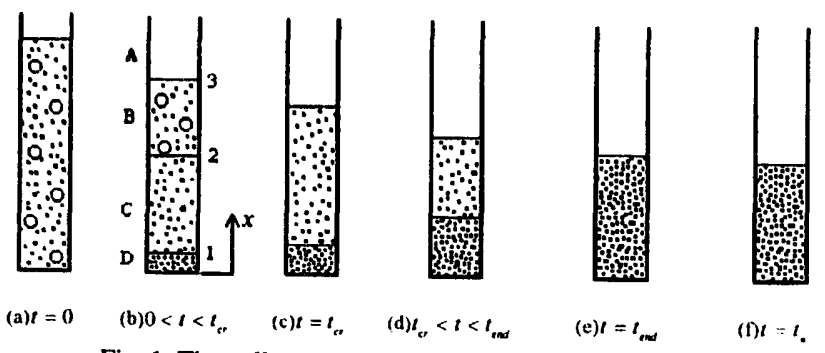

Fig. 1. The collapsing process of bubbling fluidized bed. 
rapid collapse of the bed, this stage is called bubble escape stage $\left(0<t<t_{\mathrm{cr}}\right)$. During this stage the upper section of the bed consists of bubbles, below it is a bubble-free dense phase and at the bottom of the bed is the accumulated layer built by the settled particles. At $t=t_{\mathrm{cr}}$, bubbles disappear completely, thereafter the bed surface continues to descend while the accumulated layer at the bottom ascends $\left(t_{\mathrm{cr}}<t<t_{\text {end }}\right)$. At $t=t_{\text {end }}$, all the gas in the dense phase has been expelled and the collapse process is complete. (Strictly, the bed height should descend even more owing to the consolidation of the particles, until at $t=t_{x}$ the ultimate height is reached).

We can divide the fluidized bed during the collapsing process into four regions as shown in Fig. 1(b):

Region A: the region above the bed surface;

Region B: the upper section consisting of bubbles, emulsion phase (or called dense phase) and wake;

Region C: bubble-free dense phase;

Region D: accumulated layer built by the settled particles. The interfaces of the neighboring two regions are called surface 1, surface 2 and surface 3 and their location are $x_{\mathrm{s} 1}$, $x_{\mathrm{s} 2}$ and $x_{\mathrm{s} 3}$ respectively.

Our model is based on the following assumption:

(i) the fluidized bed is made up of a bubble phase devoid of particles, emulsion phase and wake;

(ii) all the particles have a uniform dimension;

(iii) bubbles are distributed uniformly in the whole bed with the same rising velocity $u_{\mathrm{h}}$;

(iv) at any time, the bubble fraction in region $B$ is $\alpha_{b}$, the wake fraction is $\alpha_{w}$, the particle fraction in the wake phase and the dense phase in region B and C is $\alpha_{p}$, the velocity of particles in the wake is the same as the rising velocity of bubble;

(v) the consolidation of the settled particles is neglected and the fraction of particle in accumulated layer is $\alpha_{x}$;

(vi) the density of gas is constant.

\subsection{Location variation of the interfaces}

Firstly, the location variation of the three interfaces will be derived.

In region $\mathrm{B}$, if the velocity of dense phase is $u_{\mathrm{e}}$, then

$\alpha_{\mathrm{b}} u_{\mathrm{b}}+\alpha_{\mathrm{w}} u_{\mathrm{b}}+\left(1-\alpha_{\mathrm{b}}-\alpha_{\mathrm{w}}\right) u_{\mathrm{c}}=u_{\mathrm{f}}$

The derivation of Eq. (1) is shown in Appendix A. $u_{\mathrm{f}}$ is the releasing rate of the gas in the plenum chamber and can be calculated by Eq. (2) [5].

$u_{\mathrm{f}}=\left(\frac{W}{A}+\Delta P_{\mathrm{d}}\right) \frac{V_{0}}{A P_{\mathrm{u}} t_{\mathrm{end}}}$

In the dense phase of region $\mathrm{B}$, if $u_{\mathrm{g}, \mathrm{B}}$ is the gas velocity and $u_{\mathrm{p} . \mathrm{B}}$ is the average velocity of particles, then

$\left(1-\alpha_{\mathrm{p}}\right) u_{\mathrm{g} . \mathrm{B}}+\alpha_{\mathrm{p}} u_{\mathrm{p}, \mathrm{B}}=u_{\mathrm{e}}$

Additionally, the relationship between the velocities of particle and gas is: $u_{\mathrm{g}, \mathrm{B}}-u_{\mathrm{p}, \mathrm{B}}=u_{2}$

Where, $u_{\mathrm{t}}=u_{\mathrm{t}}\left(\alpha_{\mathrm{p}}\right)$, is the slip velocity of particle, Eqs. (1), (3) and (4) give:

$u_{\mathrm{p}, \mathrm{B}}=-\frac{\left(\alpha_{\mathrm{b}}+\alpha_{\mathrm{w}}\right) u_{\mathrm{b}}-u_{\mathrm{f}}}{1-\alpha_{\mathrm{b}}-\alpha_{\mathrm{w}}}-\left(1-\alpha_{\mathrm{p}}\right) \mu_{\mathrm{t}}$

In region $\mathbf{C}$ :

$\left(1-\alpha_{\mathrm{p}}\right) u_{\mathrm{g}, \mathrm{C}}+\alpha_{\mathrm{p}} u_{\mathrm{p}, \mathrm{C}}=u_{\mathrm{f}}$

$u_{\mathrm{g}, \mathrm{C}}-u_{\mathrm{p}, \mathrm{C}}=u_{\mathrm{t}}$

So,

$u_{\mathrm{p}, \mathrm{C}}=u_{\mathrm{f}}-\left(1-\alpha_{\mathrm{p}}\right) u_{\mathrm{t}}$

\subsection{1. $0 \leq t \leq t_{c r}$}

When $t<t_{\mathrm{cr}}$, the mass balance relations of solid phase at the three interfaces are:

Surface 1: $\left(u_{\mathrm{p}, \mathrm{C}}-\frac{\mathrm{d} x_{\mathrm{si}}}{\mathrm{d} t}\right) \alpha_{\mathrm{p}}=\left(u_{\mathrm{p}, \mathrm{L}}-\frac{\mathrm{d} x_{\mathrm{s} 1}}{\mathrm{~d} t}\right) \alpha_{x}$

Surface 2: $\left(u_{\mathrm{p}, \mathrm{w}}-\frac{\mathrm{d} x_{\mathrm{s} 2}}{\mathrm{~d} t}\right) \alpha_{\mathrm{w}} \alpha_{\mathrm{p}}+\left(u_{\mathrm{p}, \mathrm{B}}-\frac{\mathrm{d} x_{\mathrm{s} 2}}{\mathrm{~d} t}\right)$

$$
\times\left(1-\alpha_{\mathrm{b}}-\alpha_{\mathrm{w}}\right) \alpha_{\mathrm{p}}=\left(u_{\mathrm{p}, \mathrm{C}}-\frac{\mathrm{d} x_{\mathrm{s} 2}}{\mathrm{~d} t}\right) \alpha_{\mathrm{p}}
$$

$$
\begin{aligned}
& \text { Surface 3: }\left(u_{\mathrm{p}, \mathrm{A}}-\frac{\mathrm{d} x_{\mathrm{s}, 3}}{\mathrm{~d} t}\right) \times 0=\left(u_{\mathrm{p}, \mathrm{w}}-\frac{\mathrm{d} x_{\mathrm{s}, 3}}{\mathrm{~d} t}\right) \alpha_{\mathrm{w}} \alpha_{\mathrm{p}} \\
& +\left(u_{\mathrm{p}, \mathrm{B}}-\frac{\mathrm{d} x_{\mathrm{s}, 3}}{\mathrm{~d} t}\right)\left(1-\alpha_{\mathrm{b}}-\alpha_{\mathrm{w}}\right) \alpha_{\mathrm{p}}
\end{aligned}
$$

Where $u_{\mathrm{p}, \mathrm{w}}$ is the velocity of the particles in wake, $u_{\mathrm{p}, \mathrm{w}}=u_{\mathrm{b}}$; $u_{\mathrm{p}, \mathrm{A}}, u_{\mathrm{p}, \mathrm{D}}$ are the average velocity of particles in Region $\mathrm{A}$ and Region $\mathrm{D}$ respectively, $u_{\mathrm{p} . \mathrm{D}}=\mathbf{0}$.

Replacing $u_{\mathrm{p} . \mathrm{B}}$ and $u_{\mathrm{p}, \mathrm{C}}$ in Eqs. (9)-(11) with Eqs. (5) and (8) and integrating Eqs. (9)-(11) under the following initial conditions: $x_{\mathrm{s} 1}(0)=0, x_{\mathrm{s} 2}(0)=0, x_{\mathrm{s} 3}(0)=H_{0}$, we get:

$x_{\mathrm{s} 1}=\frac{\left[\left(1-\alpha_{\mathrm{p}}\right) u_{\mathrm{t}}-u_{\mathrm{f}}\right] \alpha_{\mathrm{p}} t}{\alpha_{\mathrm{x}}-\alpha_{\mathrm{p}}}$

$x_{\mathrm{s} 2}=u_{\mathrm{b}} t-\left(1-\alpha_{\mathrm{p}}\right)\left(1+\frac{\alpha_{\mathrm{w}}}{\alpha_{\mathrm{b}}}\right) u_{1} t$

$x_{\mathrm{s} 3}=H_{0}-\frac{\left[\alpha_{\mathrm{h}} u_{\mathrm{h}}-u_{\mathrm{f}}+\left(1-\alpha_{\mathrm{b}}-\alpha_{\mathrm{w}}\right)\left(1-\alpha_{\mathrm{p}}\right) u_{\mathrm{t}}\right] t}{1-\alpha_{\mathrm{b}}}$

When $t=t_{\mathrm{cr}}$, surface 3 is at the same location with surface 2 , that is $x_{\mathrm{s} 3}=x_{\mathrm{s} 2}$, so:

$t_{\mathrm{cr}}=\frac{H_{0} \alpha_{\mathrm{b}}\left(1-\alpha_{\mathrm{b}}\right)}{u_{\mathrm{b}} \alpha_{\mathrm{b}}-\alpha_{\mathrm{w}}\left(1-\alpha_{\mathrm{p}}\right) u_{\mathrm{t}}-u_{\mathrm{f}} \alpha_{\mathrm{b}}}$ 


$$
\begin{aligned}
& \left.x_{\mathrm{s} 3}\right|_{t=t_{\mathrm{cr}}}=\left.x_{\mathrm{s} 2}\right|_{t=t_{\mathrm{cr}}} \\
& =\frac{H_{0}\left(1-\alpha_{\mathrm{b}}\right) \alpha_{\mathrm{b}} u_{\mathrm{b}}-\left(1-\alpha_{\mathrm{p}}\right)\left(\alpha_{\mathrm{b}}+\alpha_{\mathrm{w}}\right) u_{\mathrm{t}}}{\left(u_{\mathrm{h}}-u_{\mathrm{t}}\right) \alpha_{\mathrm{h}}-\alpha_{\mathrm{w}}\left(1-\alpha_{\mathrm{p}}\right) u_{\mathrm{t}}}
\end{aligned}
$$

2.1.2. $t>t_{c} r$

When $t>t_{\mathrm{cr}}$, the mass balance on surface 2 becomes:

$\left(u_{\mathrm{p}, \mathrm{A}}-\frac{\mathrm{d} x_{\mathrm{s}}}{\mathrm{d} t}\right) \times 0=\left(u_{\mathrm{p}, \mathrm{C}}-\frac{\mathrm{d} x_{\mathrm{r} 2}}{\mathrm{~d} t}\right) \alpha_{\mathrm{p}}$

Taking Eq. (16) as the initial condition, Eq. (17) can be integrated:

$x_{12}=H_{01}\left(1-\alpha_{1}\right)-\left(1-\alpha_{p}\right) u_{1} t+u_{1} t$

On surface 1 , the mass balance relation is still expressed by Eq. (9) and its location variation can still be expressed by Eq. (12).

When $t=t_{\text {sinu }}, x_{1,1}=x_{1,2}$, so:

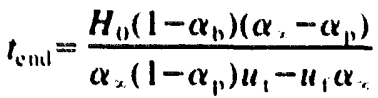

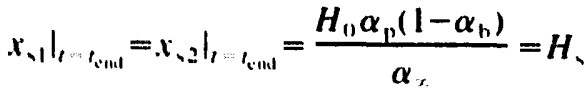

Fig. 2 is the typical plot of the location variation of the three interfaces with time. In the figure. line mpqs, opqs, and ogs correspond to surface 3 , surface 2 and surface 1 respectively.

\subsection{Pressure variation}

Now we will derive the pressure variation with time at a horizontal which is all a distance $x$ from the distributor. The momentum equations of the gas phase and the solid phase give the following ( see Appendix $B$ ).

For region $B$ and $C$ :

$\frac{\mathrm{d} p}{\mathrm{~d} x}=-(1-\varepsilon) \rho_{1} g$.

For region $D$ :

$\frac{d p}{d x}=-K u_{1}$

where.

$K=\frac{180 \mu_{2} \alpha_{2}^{2}}{d_{1}^{2}\left(1-\alpha_{2}\right)^{3}}$

Integrating Eqs. (21) and (22) from $x$ to the bed surface gives the pressure distribution $p(t, x)$ (in this article, it is the relative pressure).

When $t<t$

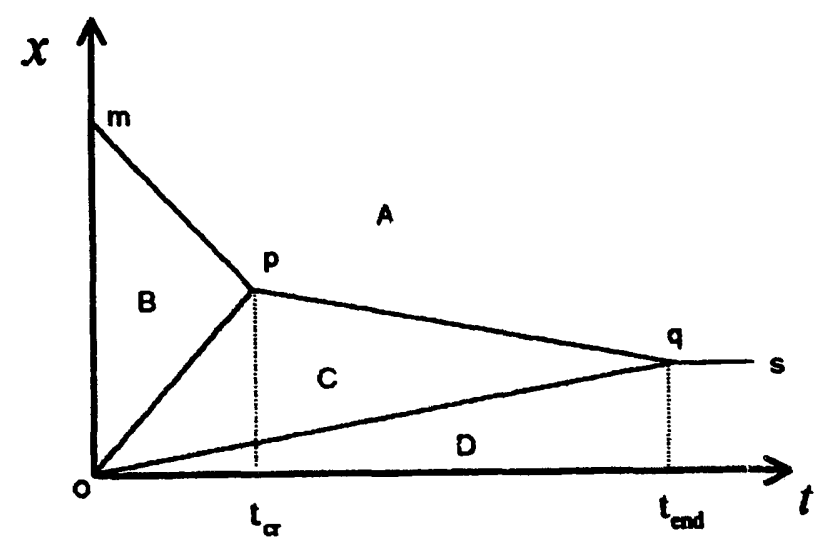

Fig. 2. Typical plot of the location variation of the three interfaces with time.

$\frac{m(n, 1)}{w_{1}, p_{1}, 4}$

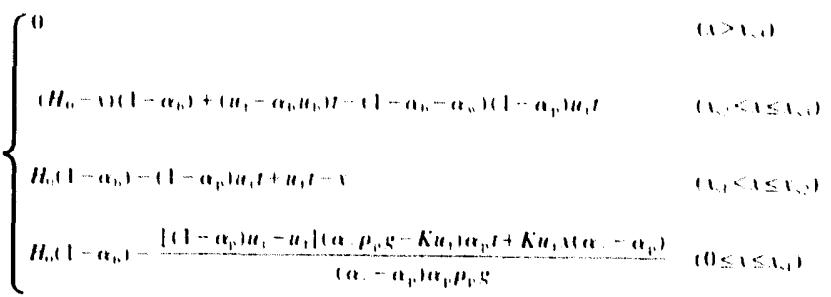

When $t \geq t_{\text {is }}$

$\frac{m 1.11}{u, m, 4}$

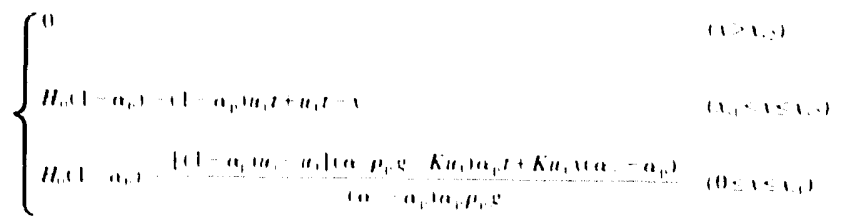

Our experiments and calculation showed that. in most case, especially when the volume of the plenum was small, $u_{1}$ was very small and had little influence on the pressure calculation, so it can be neglected and Eqs. (24) and (25) are simplified as follows:

When $t<t_{11}$,

$\frac{p(1, x)}{\alpha_{1}, \rho_{p}, g}=$

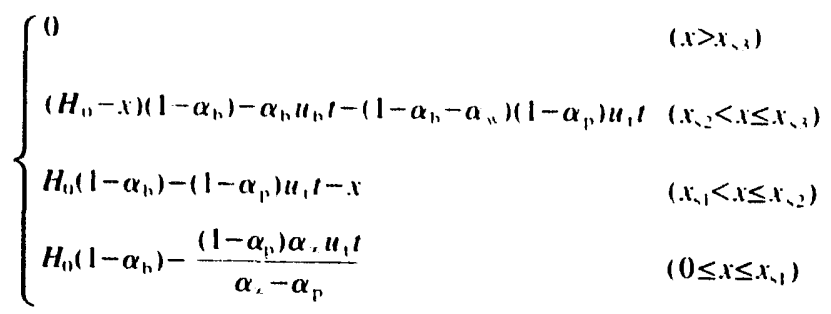

When $t \geq t_{\mathrm{cr}}$, 


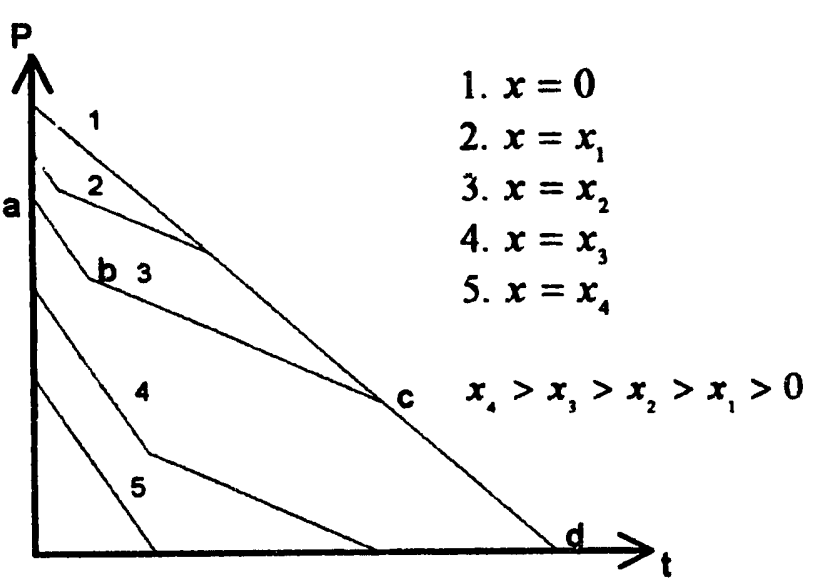

Fig. 3. Plot of $p(t)$ at different location of the bed during collapse.

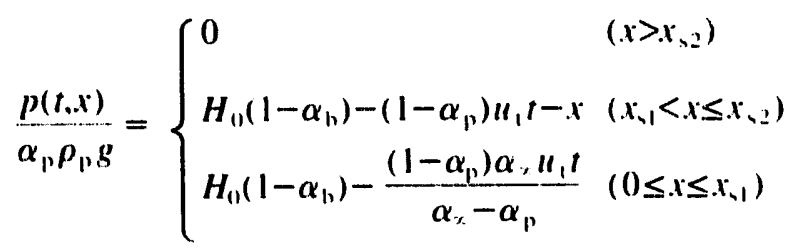

$\alpha$, in the model can be obtained by measuring the static bed height $H_{\mathrm{s}}$ and weighing the particles in the column, $H_{0}$ can be measured before collapsing. Thus there are five parameters to be cietermined in the model $\alpha_{\mathrm{b}}, \alpha_{w}, u_{\mathrm{b}}, \alpha_{\mathrm{p}}$ and $u_{1}$, and among them there are only four independent ones, because

$H_{1}\left(1-\alpha_{1}\right) \alpha_{\mathrm{p}}=H_{1} \alpha_{,}$

The pressure distribution $p(t, x)$ can be calculated by Eqs. (24) and (25) or Eqs. (26) and (27) provided that the parameters are known.

Fig. 3 is the pressure variation with time at different location of the bed during collapse according Eqs. (24) and (25). We can see that three kinds of straight lines with different slope appear on the curves. Taking the curve at $x=x_{2}$ as an example, line $a b$ corresponds to the pressure before surface 2 reaches this location and its slope can be calculated from Eq. (24):

$$
\begin{aligned}
k_{1}=\left.\frac{\mathrm{d} p}{\mathrm{~d} t}\right|_{\mathrm{u}^{\prime \prime}}= & -\left[\left(1-\alpha_{1}-\alpha_{\mathrm{w}}\right)\left(1-\alpha_{\mathrm{p}}\right) u_{1}\right. \\
& \left.+\alpha_{\mathrm{b}} u_{\mathrm{h}}-u_{\mathrm{f}}\right] \alpha_{\mathrm{p}} \rho_{\mathrm{p}} g
\end{aligned}
$$

Line $b c$ corresponds to the pressure after surface 2 reaches this location and before surface 1 reaches this location, its slope is given by Eq. (24) or Eq. (25):

$$
\begin{aligned}
k_{2} & =\left.\frac{\mathrm{d} p}{\mathrm{~d} t}\right|_{\mathrm{lc}}=-\left[\left(1-\alpha_{\mathrm{p}}\right) u_{1}-u_{\mathrm{l}}\right] \alpha_{\mathrm{p}} \rho_{\mathrm{p}} g \\
& \approx-\left(1-\alpha_{\mathrm{p}}\right) u_{1} \alpha_{\mathrm{p}} \rho_{\mathrm{p}} g
\end{aligned}
$$

Line $c d$ corresponds to the pressure after surface 1 reaches this location and its slope is given by Eq. (24) or Eq. (25):

$$
\begin{aligned}
k_{3} & =\left.\frac{\mathrm{d} p}{\mathrm{~d} t}\right|_{c d}=-\frac{\left.\mid u_{1}\left(1-\alpha_{p}\right)-u_{\mathrm{f}}\right]\left(\alpha_{,} \rho_{\mathrm{p}} g-K u_{1}\right) \alpha_{\mathrm{p}}}{\alpha_{\%}-\alpha_{\mathrm{p}}} \\
& \approx-\frac{\alpha_{\mathrm{r}}\left(1-\alpha_{\mathrm{p}}\right) u_{1} \alpha_{\mathrm{p}} \rho_{\mathrm{p}} g}{\alpha_{\%}-\alpha_{\mathrm{p}}}
\end{aligned}
$$

On the pressure curves of different location, the lines with slope $k_{1}$ are parallel and so are the lines with slope $k_{2}$, the lines with slope $k_{3}$ almost overlap on the same line.

Eqs. (30) and (31) give $\left(\left|k_{3}\right|\right) /\left(\left|k_{2}\right|\right)=\left(\alpha_{-x}\right) /\left(\alpha_{\%}-\alpha_{p}\right)$ $>1$, that is, $\left|k_{3}\right|>\left|k_{2}\right|$. During the period after surface 2 reaches the location and before surface 1 reaches the location, what leads to the pressure variation is the descent of surface 2; After surface 1 reaches the location, both the descent of surface 2 and the ascent of surface 1 affects the pressure variation. So pressure descends faster after surface 1 reaches the location than before surface ! reaches the location, namely, $\left|k_{3}\right|>\left|k_{2}\right|$.

It has been reported that the voidage of dense phase and the interstitial gas velocity can be obtained by following the variation of the bed height during collapse $[1,2]$. Similarly, the parameters of a fluidized bed can also be obtained by measuring the pressure variation during collapse.

The particle fraction in dense phase $\alpha_{p}$ and the slip velocity of particle $u_{1}$ can be calculated by using Eqs. (30) and (31) after we know slope $k_{2}$ and $k_{3}$ from the pressure variation curves obtained experimentally, the bubble fraction $\alpha_{b}$ can then be calculated by using Eq. (28).

In order to calculate $u_{\mathrm{b}}$, taking $\alpha_{\mathrm{b}}=3 \alpha_{\mathrm{w}}[10]$, then $u_{\mathrm{b}}$ can be obtained by using Eq. (29) after we know $k_{l}$ from the experimental curves.

\section{Experimental}

Fig. 4 is the schematic diagram of the experimental apparatus. The experiments were carried out under ambient conditions in a $70 \mathrm{~mm}$ ID and $870 \mathrm{~mm}$ height perspex column fitted with a porous plate distributor. The pressures in the plenum chamber and on different location of the bed were measured simultaneously by five pressure transducers and the signal was collected and treated by a computer after mag-

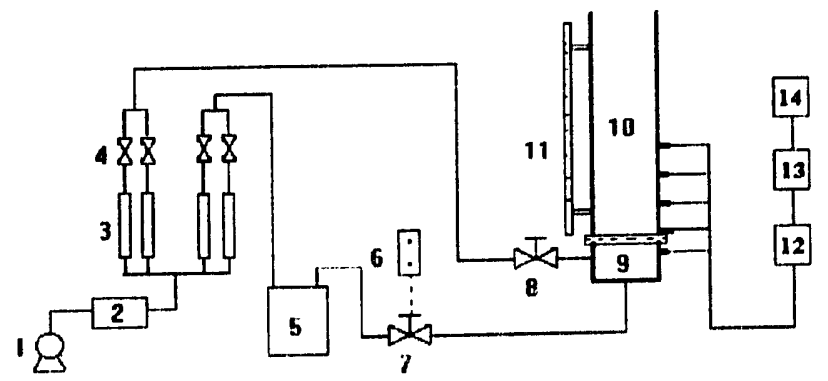

Fig. 4. Schematic diagram of the experimental apparatus: 1, air compressor: 2. dryer: 3, rotameter: 4, needle valve: 5, surge tank: 6, time-lag relay: 7 and 8 , solenoid valve: 9 , plenum chamber; 10 . fluidized bed: 11 , ruler: 12. pressure transducer: 13, A/D converter: 14, Computer. 
Table 1

Physical properties of the solid used

\begin{tabular}{llll}
\hline Particle & $\begin{array}{l}d_{\mathrm{p}} \\
(\mu \mathrm{m})\end{array}$ & $\begin{array}{l}\rho_{\mathrm{v}} \\
\left(\mathrm{kg} / \mathrm{m}^{3}\right)\end{array}$ & $\begin{array}{l}u_{\mathrm{mf}} \\
(\mathrm{m} / \mathrm{s})\end{array}$ \\
\hline FCC-I & 70 & 1598 & 0.007 \\
FCC-II & 50 & 1020 & 0.001 \\
Sand & 210 & 2600 & 0.030 \\
\hline
\end{tabular}

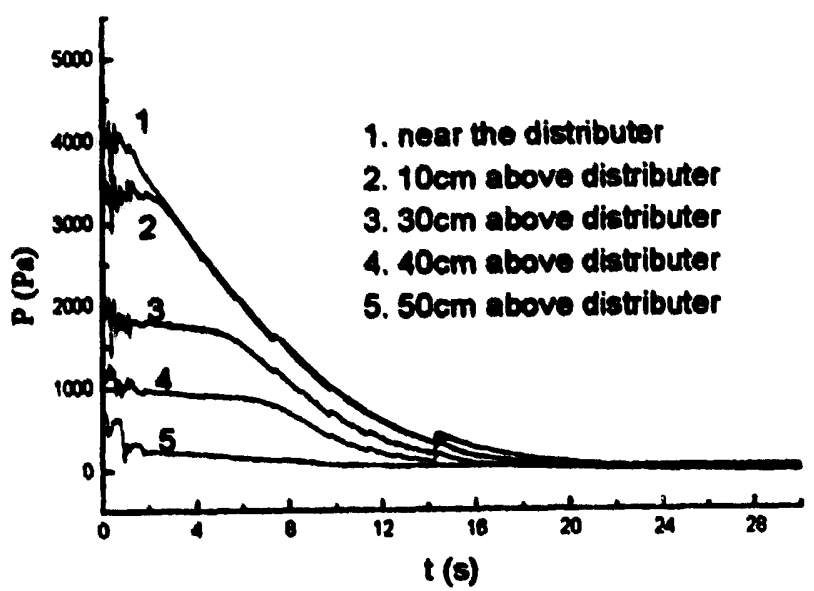

Fig. 5. Measured pressure variation during collipse: (1800 g FCC-I. $\left.u_{\mathrm{p}}=4 u_{u t u t}\right)$.

nification and A/D conversion. The gas used was air. The solids used and their properties are shown in Table $\mathrm{I}$.

\subsection{Bed collapse}

Particles were fluidized at a certain gas velocity and the initial bed height $\boldsymbol{H}_{0}$ was measured, then the gas supply was terminated by turning off the solenoid valve and the pressure was recorded. The static bed height $\boldsymbol{H}$, was measured after collapsing completed. The sampling frequency is $100 \mathrm{~Hz}$. One of the measured pressure curves is shown in Fig. 5.

\subsection{Pulsed fluidization}

Particles were fluidized by pulsed gas. The average gas velocity was controlled by the rotameter, the pulse frequency and the duration ratio were controlled by the graded time-lag relay. The pressure variations at different bed location were recorded by pressure transducers and the sampling frequency was $100 \mathrm{~Hz}$.

\section{Results and discussion}

\subsection{Parameters estimation from the pressure curves}

Comparing Figs. 3 and 5, we can see that the measured pressure variation curves are very similar to the curves calculated by using the model. $\alpha_{\mathrm{b}}, \alpha_{\mathrm{p}}, u_{\mathrm{b}}$ and $u_{\mathrm{t}}$ can be estimated after the slopes of the lines on the curves are measured.
Table 2

Results of the estimation of fluidization parameters

\begin{tabular}{llllll}
\hline Particle & $\begin{array}{l}u_{\mathrm{g}} \\
(\mathrm{m} / \mathrm{s})\end{array}$ & $\alpha_{\mathrm{b}}$ & $\begin{array}{l}u_{\mathrm{b}} \\
(\mathrm{m} / \mathrm{s})\end{array}$ & $\alpha_{\mathrm{p}}$ & $\begin{array}{l}u_{\mathrm{i}} \\
(\mathrm{m} / \mathrm{s})\end{array}$ \\
\hline FCC-I & 0.014 & 0.01 & $?$ & 0.53 & 0.008 \\
& 0.028 & 0.09 & 0.29 & 0.53 & 0.008 \\
& 0.070 & 0.11 & 0.40 & 0.53 & 0.008 \\
FCC-II & 0.007 & 0.06 & $?$ & 0.48 & 0.005 \\
Sand & 0.10 & 0.16 & $?$ & 0.52 & 0.18 \\
\hline
\end{tabular}

On the measured curves, the segment, which should be a line with slope $k_{1}$, is not a straight line due to the fierce pressure fluctuation during the bubble escape stage. $k_{1}$ can be obtained by line-fitting of the experimental data and the experiments should be repeated for several times under the same conditions in order to improve the precision.

The estimated results of a fluidized bed with different particles and different gas velocity are shown in Table 2 . In some tests, $u_{\mathrm{b}}$ is not obtained because of the difficulty of calculating $k_{1}$.

\subsection{Simulation of collapsing process}

The collapsing process can be simulated by using the proposed model if $\alpha_{\mathrm{b}}, \alpha_{\mathrm{w}}, u_{\mathrm{h}}, \alpha_{\mathrm{p}}$ and $u_{\mathrm{t}}$ are given (only four parameters are independent).

Fig. 6 is the comparison between the simulated and measured pressure variation on different locations of the bed. We can see that the simulated results are in good agreement with the measured results except for the period near the completion of collapse.

\subsection{Simulation of pulsed fluidized bed}

If the pulse frequency is low, during the on-period of the pu!sed fluidization, the bed is in a state of fluidization. During the off-period, it is a bed-collapsing process. Therefore the pressure variation during the off-period can be calculated by Eqs. (24) and (25). During the on-period, a certain time is neecled to establish the steady state of fluidization and the bed height varies considerably. Meanwhile, the pressure fluctuates greatly due to the existence of bubbles. If the pulse frequency is low, the time for the establishment of the steady fluidization is relatively short. For simplicity, we neglect the period for establishing steady fluidization and assume that the bed height and the pressure are steady, so the pressure at a distance $x$ from the distributor during on-period can be calculate by the following equation:

$p(x)=\left(H_{0}-x\right)\left(1-\alpha_{\mathrm{b}}\right) \alpha_{\mathrm{p}} \rho_{\mathrm{p}} g$

Then the pressure variation in the pulsed fluidized bed can be simulated by using Eqs. (24), (25) and (32). Fig. 7 is the comparison of the simulated results and the experimental 

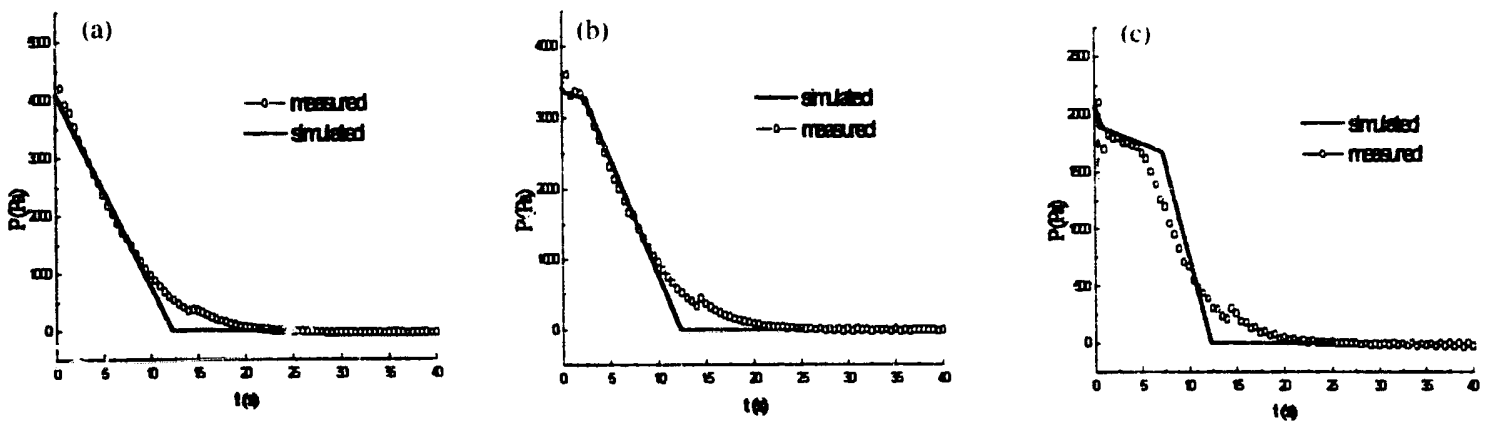

Fig. 6. Comparison between measured and simulated results: (a) near the distributor; (b) $10 \mathrm{~cm}$ above the distributcr; (c) $30 \mathrm{~cm}$ above the distributor.
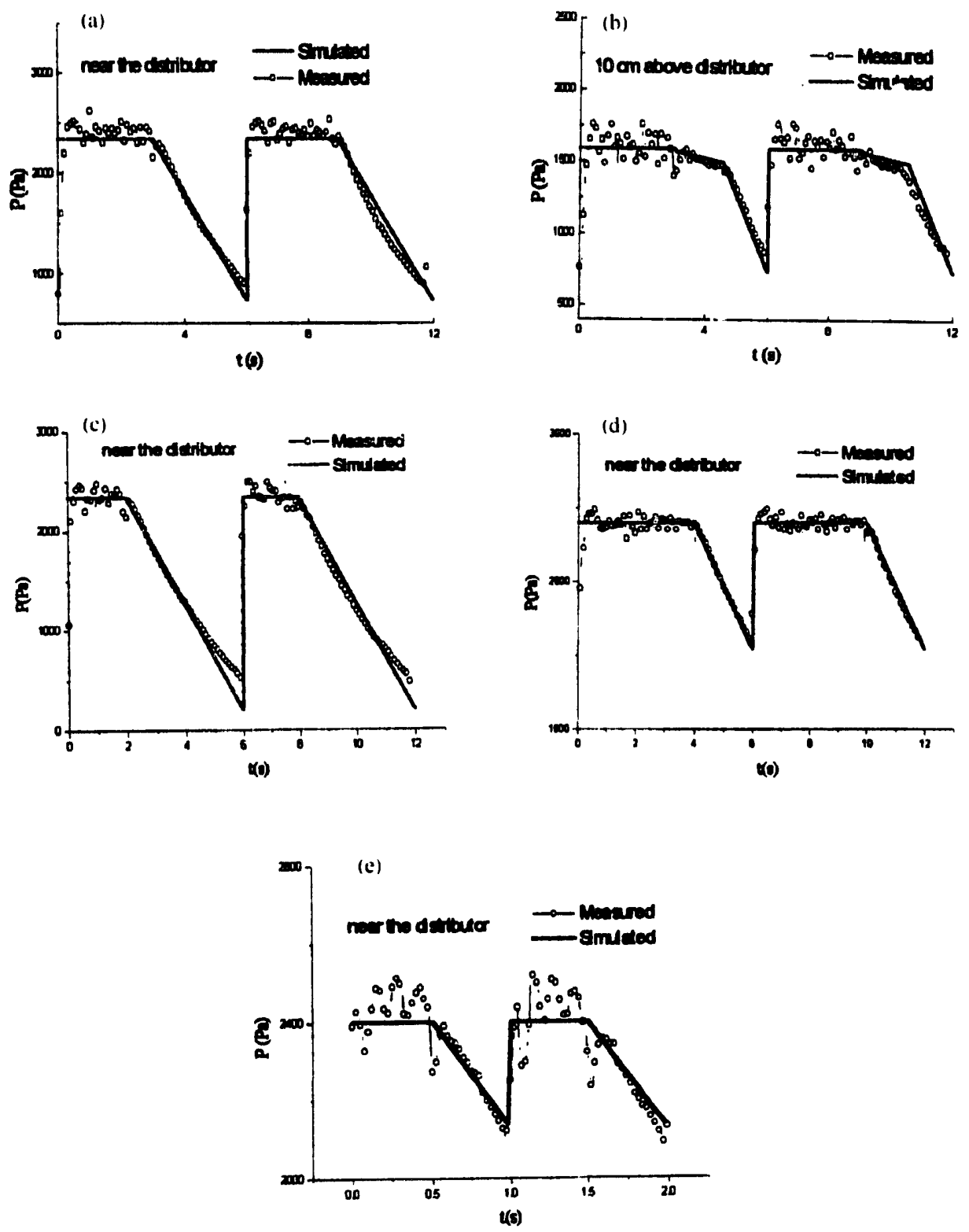

Fig. 7. Comparison brtween the simulated and measured pressure variation in pulsed bed with different frequency and duration ratio. (a, b) $f=0.16 \mathrm{H} z$, onperiod $=3.0 \mathrm{~s}$, off-pen $) d=3.0 \mathrm{~s}$; (c) $f=0.16 \mathrm{~Hz}$, on-period $=2.0 \mathrm{~s}$, off-period $=4.0 \mathrm{~s}:$ (d) $f=0.16 \mathrm{~Hz}$. on-period $=4.0 \mathrm{~s}$, off-period $=2.0 \mathrm{~s}$, (e) $f=1.0 \mathrm{~Hz}$, on-period $=0.5 \mathrm{~s}$, off-pt iod $=0.5 \mathrm{~s}$.

data of pulsed bed with different frequency and duration ratio. We can see that the simulated results are in good agreement with the measured results when the pulse frequency is low.
When the pulse frequency is high, the simplified approach is unsuitable because the effect of the period for establishing steady fluidization can not be neglected. 


\section{Conclusions}

A new method to study the collapsing process of fluidized beds was proposed. The gas-particle flow in fluidized bed was described by a three-phase model (bubble, emulsion and wake), the collapsing process was analyzed and a model was proposed to calculate the pressure variation at different bed location during collapsing. The model was used to simulate the collapsing process and the simulated results are in good agreement with the measured results. The parameters of fluidized beds, such as bubble fraction $\alpha_{h}$, particle fraction in dense phase $\alpha_{p}$, bubble rising velocity $u_{h}$ and slip velocity of particle $u_{1}$ can be estimated from the experimental data by using the proposed model.

When the pulse frequency is low, the pulsed fluidized bed nan be regarded as a combination of a steady fluidization (onperiod) and a collapsing process (off-period), the pressure variation can be calculated by Eqs. (24), (25) and (32).

Compared with the conventional method which studies the collapsing process by measuring the bed height variation, recording the pressure variation is a more convenient way to study the collapsing process, furthermore, it can provide more information.

\section{Notation}

A sectional area of the bed $\left(\mathrm{m}^{2}\right)$

$H_{1} \quad$ initial bed height ( $\mathrm{m}$ )

$H$, stotic bed height $(\mathrm{Pa})$

$p \quad$ pressure $(\mathbf{P a})$

$P_{\text {il }} \quad$ atmospheric pressure $(\mathrm{Pa})$

$P_{111} \quad$ pressure in plenum $(\mathrm{Pa})$

$t_{\text {ir }} \quad$ critical time (s)

$t_{\mathrm{c} n t} \quad$ time of the end of the collapsing (s)

$u_{h}$ bubble velocity ( $\mathrm{ms}{ }^{1}$ )

$u_{\mathrm{g}} \quad$ superficial gas velocity ( $\mathrm{m} \mathrm{s}{ }^{\prime}$ )

$u_{n+1} \quad$ initial fluidization velocity ( $\mathrm{m} \mathrm{s}{ }^{\prime}$ )

$u_{p} \quad$ particle velocity ( $\mathrm{ms} \mathrm{s}^{-1}$ )

$\|_{1} \quad$ slip velocity of particles ( $\mathrm{m} \mathrm{s}{ }^{\prime}$ )

$V_{11} \quad$ volume of the plenum $\left(\mathrm{m}^{3}\right)$

$W$ weight of particle in the column ( $N$ )

$x$ coordinate $(m)$

$\alpha_{1} \quad$ bubble fraction

$\alpha_{n} \quad$ particle fraction in dense phase

$\alpha_{w} \quad$ wake fraction

$\alpha_{x} \quad$ particle fraction in settled phase

P. particle density ( $\left.\mathrm{kg} \mathrm{m}^{-3}\right)$

$\Delta \boldsymbol{P}_{\mathrm{d}} \quad$ pressure drop across distributor $\left(\mathrm{Pa}_{\mathrm{a}}\right)$

$\mu_{z} \quad$ viscosity coefficient ( $P a s$ )

\section{Acknowledgements}

This work is supported by the Multiphase Reaction Lab-

\section{Appendix A}

\section{Derivation of Eq. (1)}

The continuity equation for particle is:

$\frac{\partial\left(\varphi_{\mathrm{p}} \rho_{\mathrm{p}}\right)}{\partial t}+\frac{\partial\left(\varphi_{\mathrm{p}} \rho_{\mathrm{p}} U_{\mathrm{p}}\right)}{\partial x}=0$

Where $\varphi_{p}$ is the averaged volume fraction of particle (include the particles in bubble, wake and dense phase), $U_{\mathrm{p}}$ is the averaged velocity of particle.

The continuity equation for gas is:

$\frac{\partial\left[\left(1-\varphi_{\mathrm{p}}\right) \rho_{\mathrm{g}}\right]}{\partial t}+\frac{\partial\left[\left(1-\varphi_{\mathrm{p}}\right) \rho_{\mathrm{g}} U_{\mathrm{g}}\right]}{\partial x}=0$

Where $U_{\mathrm{g}}$ is the averaged velocity of gas.

Because the density of particle and the density of gas are constant, Eqs. (al) and (a2) can be expressed as:

$\frac{\partial \varphi_{\mathrm{p}}}{\partial t}+\frac{\partial\left(\varphi_{\mathrm{p}} U_{\mathrm{p}}\right)}{\partial x}=0$

$\frac{\partial\left(1-\varphi_{\mathrm{p}}\right)}{\partial t}+\frac{\partial\left[\left(1-\varphi_{\mathrm{p}}\right) U_{\mathrm{g}}\right]}{\partial x}=0$

Adding Eqs. (a3) and (a4):

$\frac{\partial\left[\varphi_{n} U_{p}+\left(1-\varphi_{n}\right) U_{\mathrm{n}}\right]}{\partial x}=0$

So,

$\varphi_{1} U_{\mathrm{p}}+\left(1-\varphi_{\mathrm{p}}\right) U_{\mathrm{g}}=\mathrm{constant}$

Eq. (a5) can be applied to both steady and unsteady gassolids flow, including collapse process. For a collapsing fluidized bed,

$$
\begin{aligned}
& \varphi_{p} U_{p}=\alpha_{n}\left(1-\varepsilon_{n}\right) u_{n}+\left(1-\alpha_{1}-\alpha_{w}\right) \alpha_{p}, u_{p . B}\left(1-\varphi_{p}\right) U_{k} \\
& =\alpha_{h} u_{n}+\alpha_{w} \varepsilon_{w} u_{h}+\left(1-\alpha_{h}-\alpha_{w}\right)\left(1-\alpha_{p}\right) u_{\mathrm{g} .13}
\end{aligned}
$$

Eq. (a5) becomes:

$$
\begin{aligned}
& \alpha_{1,} u_{n}+\alpha_{w} u_{n}+\left(1-\alpha_{n}-\alpha_{w}\right)\left[\alpha_{p} u_{p . B}+\left(1-\alpha_{p}\right) u_{\mathrm{g} . \mathrm{B}}\right] \\
& =u_{1}
\end{aligned}
$$

If the velocity of dense phase is $u_{\mathrm{c}}$, then

$\alpha_{p} u_{p, B}+\left(1-\alpha_{p}\right) u_{g, \mathrm{~B}}=u_{\mathrm{c}}$

Replacing Eq. (a7) into Eq. (a6):

$\alpha_{1} u_{1}+\alpha_{w} u_{b}+\left(1-\alpha_{1}-\alpha_{w}\right) u_{c}=u_{\text {f }}$

\section{Appendix B}

Derivation of the pressure distribution during collapsing 
$\varepsilon \rho_{\mathrm{g}} \frac{d_{\mathrm{g}} u_{\mathrm{g}}}{\mathrm{d} t}=-\varepsilon \frac{\mathrm{d} p}{\mathrm{~d} x}-\varepsilon \rho_{\mathrm{g}} g-F_{\mathrm{D}}+\frac{4 \tau_{\mathrm{w}, \mathrm{g}}}{D_{\mathrm{b}}}$

$$
\begin{aligned}
(1-\varepsilon) \rho_{\mathrm{p}} \frac{d_{\mathrm{p}} u_{\mathrm{p}}}{\mathrm{d} t}= & -(1-\varepsilon) \frac{\mathrm{d} p}{\mathrm{~d} x}-(1-\varepsilon) \rho_{\mathrm{g}} g+F_{\mathrm{D}} \\
& +\frac{4 \tau_{\mathrm{w} \cdot \mathrm{p}}}{D_{\mathrm{b}}}-\frac{\mathrm{d} p_{\mathrm{p}, \mathrm{f}}}{\mathrm{d} x}-\frac{\mathrm{d} p_{\mathrm{p} . \mathrm{c}}}{\mathrm{d} x}
\end{aligned}
$$

combining Eq. (b1) with Eq. (b2) gives the momentum equation of mixture:

$$
\begin{gathered}
(1-\varepsilon) \rho_{\mathrm{p}} \frac{d_{\mathrm{p}} u_{\mathrm{p}}}{\mathrm{d} t}+\varepsilon \rho_{\mathrm{g}} \frac{d_{\mathrm{g}} u_{\mathrm{g}}}{\mathrm{d} t}=-\frac{\mathrm{d} p}{\mathrm{~d} x}-(1-\varepsilon) \rho_{\mathrm{p}} g \\
-\varepsilon \rho_{\mathrm{g}} g+\frac{4\left(\tau_{\mathrm{w}, \mathrm{p}}+\tau_{\mathrm{w}, \mathrm{g}}\right)}{D_{\mathrm{h}}}-\frac{\mathrm{d} p_{\mathrm{p}, t}}{\mathrm{~d} x}-\frac{\mathrm{d} p_{\mathrm{p}, \mathrm{i}}}{\mathrm{d} x}
\end{gathered}
$$

where $\varepsilon$ is the average voidage (if bubbles exist, it is the average including bubble and emulsion phase), $F_{D}$ is the average force between gas and particle in unit volume of mixture; $\tau_{w, p}$ and $\tau_{w, p}$ are the wall friction acting on gas phase and solid phase respectively; $p_{\mathrm{p} . \mathrm{f}}$ is the stress due to the random motion of particles including collision stress; $p_{\mathrm{p} . \mathrm{c}}$ is the stress due to the contact of particles

In region $A$,

$\varepsilon=1$;

In region $B$,

$\varepsilon=\alpha_{\mathrm{h}}+\left(1-\alpha_{\mathrm{h}}\right)\left(1-\alpha_{\mathrm{p}}\right), \quad p_{\mathrm{p} . \mathrm{c}}=0$,

$\mathrm{d} p_{\mathrm{p}, \mathrm{l}} / \mathrm{d} x=0, \quad d_{\mathrm{p}} u_{\mathrm{p}} / \mathrm{d} \cdot \mathrm{x}=0, \quad d_{\mathrm{g}} u_{\mathrm{g}} / \mathrm{d} t=0 ;$

In region $\mathrm{C}$,

$\varepsilon=1-\alpha_{\mu}, \quad p_{p, c}=0, \quad \mathrm{~d} p_{p, 1} / \mathrm{d} x=0$.

$d_{p} u_{\gamma} / \mathrm{d} v=0 . \quad d_{v} u_{p} / \mathrm{d} t=0$

In region $\mathrm{D}$.

$\varepsilon=1-\alpha, \quad d_{\mathrm{z}} u_{\mathrm{g}} / \mathrm{d} t=0, \quad u_{\mathrm{p}}=0, \quad p_{\mathrm{p}, \mathrm{t}}=0$.
Neglecting $\tau_{w, p}, \tau_{u, g}$ and the gravity of gas, and using above relations, Eqs. (b1) and (b2) become

$0=-\varepsilon \frac{\mathrm{d} p}{\mathrm{~d} x}-F_{\mathrm{D}}$

$0=-(1-\varepsilon) \frac{\mathrm{d} p}{\mathrm{~d} x}-(1-\varepsilon) \rho_{\mathrm{p}} g+F_{\mathrm{D}}-\frac{\mathrm{d} p_{\mathrm{p} . \mathrm{c}}}{\mathrm{d} x}$

then the momentum equation of mixture is:

$0=-\frac{\mathrm{d} p}{\mathrm{~d} x}-(1-\varepsilon) \rho_{\mathrm{p}} g-\frac{\mathrm{d} p_{\mathrm{p} . \mathrm{c}}}{\mathrm{d} x}$

In region $\mathrm{B}$ and $\mathrm{C}, p_{\mathrm{p} . \mathrm{c}}=0$, Eq. ( $\left.\mathrm{b} 6\right)$ gives:

$\frac{\mathrm{d} p}{\mathrm{~d} x}=-(1-\varepsilon) \rho_{\mathrm{p}} g$

In region $\mathrm{D}$, Carman-Kozeny equation gives:

$\frac{\mathrm{d} p}{\mathrm{~d} x}=-\frac{180 \mu_{\mathrm{g}} \alpha_{\%}^{2}}{d_{p}^{2}\left(1-\alpha_{x}\right)^{3}}=-K u_{1}$

where, $K=\left(180 \mu_{\mu^{2}} \alpha_{x^{2}}{ }^{2}\right) /\left(d_{\mathrm{p}}{ }^{2}\left(1-\alpha_{x_{x}}\right)^{3}\right)$

\section{References}

[1] K. Rietema, Pro. Int. Symp. On Fluidization. Toulouse, 1967, p. 28

[2] G.F. Barreto, G.D. Mazza, Chem. Eng. Sci. 43 (11) (1988) 3037.

[3] R. Abrahamsen, D. Geldart, Powder Technology 26 ( 1980) 47.

[4] S. Morlka, Y. Kato, Kagaku Kogaku 37 (5) (1973) 485.

15] Y. Tung, M. Kwauk. Fluidization, Science and Technology. Gordon and Breach, New York, 1982, p. 155.

[6] M. Kwauk, Fluidization. Chap. 14. Science Press, Beijing. 1992.

17) S.Z. Qin. G.Y. Liu, et al., Engineering Chemical and Metallurgy (China) 3 (198.3) 17 .

[8] H.W. Wong, M.H.I. Baird. Chem. Eng. J. 2 (1971) 104.

(9) M. Kobayashi. D. Ramaswami, W.T. Brazelton, Chem. Eng. Prog. Sym. Ser. 6o (105) (1970) 58 .

[10] P.N. Rowe. B.A. Partridge, Trans. Instm. Chem. Engrs. 43 (1965) 157. 